\title{
Tórax y S.N.C.
}

\section{Toxicidad y tratamiento de soporte en oncología radioterápica; pulmón}

\author{
F. Casas, S. Jorcano, I. Planas, J. Marruecos, N. Viñolas
}

\section{Introducción}

El principal fin del tratamiento oncológico es erradicar la enfermedad neoplásica sin comprometer la calidad de vida del paciente. Así la combinación óptima de quimioterapia y radioterapia estará basada en el equilibrio entre su efectividad antitumoral y la morbilidad en tejidos sanos vecinos. En definitiva la agresividad del tratamiento sólo podrá ser determinada mediante el conocimiento de la tolerancia aguda de los tejidos sanos, así como de la afectación tardía que pueda acontecer posteriormente. Actualmente, inmersos en una era de múltiples tratamientos combinados, la toxicidad puede presentarse en pacientes que han recibido dosis consideradas como "seguras" de cada uno de los tratamientos administrados y las reacciones pueden ocurrir tras un periodo de tiempo indeterminado y de forma impredecible.

Entre estas pueden incluirse las siguientes:

1. Los efectos perjudiciales o dañinos de la radiación en un tejido diana pueden verse incrementados por la quimioterapia.

2. Los efectos de la quimioterapia en la zona diana pueden verse incrementados por la irradiación (por ejemplo la supresión a nivel de la médula ósea).

3. Las alteraciones que de manera independiente cada uno de ellos pueden causar en el mismo órgano pueden combinarse e incrementar el grado de disfunción (por ejemplo la cardiopatía tras la radioterapia y la doxorubicina).

4. Una agresión o lesión puede producirse sin que sea común con ninguna de las dos modalidades, por separado.

Las dificultades inherentes en entender estas consecuencias se ven por otra parte complicadas por el número de agentes quimioterápicos susceptibles de ser usados y combinados en protocolos de tratamiento, así como también por el

Servicio Oncología Radioterápica y Oncología Médica (ICMHO)

Hospital Clínic

Barcelona uso de técnicas no convencionales de irradiación (por ejemplo el hiperfraccionamiento). Aunque existen modelos de experimentación que examinan los efectos en los tejidos normales que pueden ser causados por cada agente quimioterápico y por la irradiación, no se dispone de datos evidentes dosis respuesta si no de observaciones clínicas.

\section{Definiciones de morbilidad aguda y crónica}

Las complicaciones agudas y tempranas serán aquellas que pueden aparecer durante o en unos días posteriores al tratamiento. Las que aparecen durante el tratamiento pueden ser abordables modificando aquel o mediante tratamientos de soporte planificados para este fin.

Las complicaciones tardías o crónicas son aquellas secuelas que tienen su inicio meses o incluso años tras la finalización del tratamiento. Toda decisión terapéutica que se pueda tomar para obviar éstos efectos podrá estar sólo basada en la probabilidad y no en la certeza que estos eventos puedan ocurrir.

La relación entre la lesión aguda y los efectos tardíos es impredecible. Toda terapia que es lo suficientemente intensa para causar morbilidad aguda puede ocasionar efectos crónicos. Las características estructurales de ciertos tejidos son de tal manera que esta secuencia puede no ocurrir. Incluso la ausencia de cualquier problema agudo no significa, que puedan ocasionarse efectos tóxicos a más largo plazo. La relación entre efectos agudos y tardíos, y el papel que el tratamiento combinado juega en su desarrollo puede ser analizada de una forma más correcta reconociendo las diferencias que existen entre las reacciones clínicas y subclínicas. Es obvio que las reacciones deben ocurrir sobre una alteración subclínica a fin de que esta pueda ser observada de manera adecuada. A su vez las reacciones clínicas han de tener una base subclínica.

La administración de cualquier quimioterápico o de radioterapia causa lesiones celulares, la reparación de las cuales difícilmente se produce en su totalidad. Dependiendo de la severidad de la lesión inicial (en función de la dosis de radiación o del tipo y dosis del quimioterápico empleado), en un órgano o tejido, quedará un residuo del daño. Esta lesión subclínica puede no ser apreciable hasta la siguiente administración de una dosis, aparentemente segura, de otro trata- 
miento. En este sentido, no debemos olvidar que si bien la morbilidad aguda puede limitarnos la administración completa y correcta de un tratamiento combinado la tardía, por su parte, puede comportar una alteración importantísima en la calidad de vida del paciente como sería el caso de una neumonitis secundaría al tratamiento combinado en un paciente con una neoplasia de pulmón y con previos problemas respiratorios. El hecho que no podamos detectar con facilidad los cambios morfológicos que se producen en una amplia variedad de tejidos con posterioridad a la administración de una determinada modalidad terapéutica, no nos ha de dar la falsa impresión que los inmediatos cambios celulares y ultraestructurales son sólo temporales y reversibles. Es sólo cuando éstos tejidos reciben un tratamiento adicional que los efectos residuales persistentes son clínicamente demostrables.

Desde hace mucho tiempo se han hecho considerables esfuerzos destinados tanto a definir como a cuantificar los efectos tóxicos del tratamiento combinado de radioquimioterapia. En oncología radioterápica los órganos y los tejidos se han subclasificado en función de su dosis de tolerancia (TD $5 / 5$ y TD $50 / 5$ que son la probabilidad del 5 y del $50 \%$ respectivamente, que una determinada dosis produzca complicaciones en los 5 años posteriores al tratamiento. Así dosis por debajo del TD 5/5 son consideradas como "seguras", pero siempre en relación al volumen relativo del órgano o tejido irradiado'. El concepto de los histogramas dosisvolumen será muy útil en el momento de sopesar el factor volumen cuando se desee hacer la predicción de una dosis "segura". Sin asumir, no obstante, la acción de otros tratamientos competitivos como la quimioterapia. Por su parte los intentos de cuantificar que dosis de quimioterapia pueden estar relacionadas con determinadas toxicidades se han elaborado en forma de dosis acumuladas administradas en un determinado periodo de tiempo. De forma experimental, en el laboratorio, se ha intentado cuantificar el efecto combinado de la quimioterapia y de la radioterapia a nivel de los efectos en los tejidos sanos, en relación a un factor llamado dosis-efecto $(D E F)^{2}$. Esta potenciación, medida mediante esta $\mathrm{DEF}$, se describe mediante la siguiente fórmula:

efecto biológico en relación a la dosis de radiación sin quimioterápico

$\mathrm{DEF}=$

efecto biológico en relación a la dosis de radiación con quimioterápico

Por su parte esta fórmula también puede utilizarse para aplicarla a respuesta clínica a nivel de tumor. Así para tumores seria deseable una $D E F>1$, en la cual la mortalidad de las células tumorales se produciría a menores dosis de radiación en presencia de quimioterapia que en su ausencia. Por el contrario, en relación a los tejidos normales, sería deseable una DEF lo más baja posible, que fuera menor que la DEF para los tumores. Es esta diferencia relativa entre estas dos DEF lo que se conoce como ganancia o índice terapéutico, en la cual la combinación de quimioterapia y radioterapia tienen un mayor efecto relativo a nivel del tumor que en los tejidos sanos que no cuando cualquiera de los dos tratamientos se administra por separado. Al considerar el potencial de la ganancia terapéutica de la adición de un tipo de tratamiento a otro, es importante recordar que un incremento de la mortalidad celular sólo será importante si no va acompañada de una equivalente o mayor toxicidad a nivel de tejidos sanos.

Las variables relevantes a las reacciones a nivel de los tejidos normales incluyen factores en relación al paciente, al tratamiento y al propio tumor. Una variable terapéutica adicional y específicamente relevante en la interacción de quimioterapia y radioterapia es la "temporalidad" de administración de cada uno de ellos. Existe cierta variedad de posibles interacciones entre estos dos tratamientos, cuya finalidad es incrementar el índice terapéutico. Entre éstas destacamos las siguientes:

1. Actividad independiente o también conocida como cooperación espacial ${ }^{3}$, en la cual cada tipo de tratamiento actúa en solitario en diferentes partes del cuerpo. La radioterapia erradica localmente al tumor primario, mientras la quimioterapia se dirige contra la enfermedad sistémica más allá del volumen tumoral local. Esta cooperación espacial ocurre en ausencia de cualquier interacción buscada entre ambos tratamientos.

2. Actividad incrementada en la cual la mortalidad de las células tumorales está incrementada más allá de la que se pudiera alcanzar con cualquiera de los dos tratamientos, aunque no sucede lo mismo a nivel de los tejidos normales. Los mecanismos de mortalidad celular tumoral pueden ser los mismos o diferentes, pero en relación con la toxicidad en las células normales lo ideal es que sea diferente para cada agente terapéutico para que así no sea necesaria la reducción de dosis de ninguno de los dos. En esta categoría se pueden incluir los siguientes efectos:

(a) Efectos subaditivos por los cuales la mortalidad de las células tumorales sería mayor que la esperada por cualquiera de los dos tratamientos por separado pero menor que la que se podría esperar por la combinación.

(b) Efectos aditivos en los cuales la mortalidad tumoral sería la esperada por la simple suma o adición de cada uno de los tratamientos.

(c) Efectos aumentados, supraditivos o verdadero sinergismo que ocurre cuando la mortalidad tumoral va más allá de la que se podría esperar por la simple suma de los efectos de los dos tratamientos. En la práctica es muy difícil identificar cual de las acciones ha predominado ya que aún son poco conocidas las curvas dosis respuesta específicas para cada tratamiento.

3. Actividad disminuida, en la cual existe una interferencia de los efectos de un tipo de tratamiento por el otro de tal manera que la mortalidad tumoral es menor de la esperada por uno o los dos tratamientos administrados.

\section{Mecanismos de interación}

Se sabe que el daño celular por la irradiación se causa por el impacto directo de los fotones dañando el DNA celular, y de manera indirecta mediante radicales libres cuya formación causa a su vez un nuevo daño al DNA. Es plausible inferir que los agentes quimioterápicos citotóxicos puedan interferir con las reacciones mediadas por la radiación 


\section{F. Casas y cols.}

a ese nivel, mediante estabilización de esos radicales libres, por inhibición enzimática u otros mecanismos. Las curvas de supervivencia tumoral por irradiación en diferentes líneas celulares son muy similares, con un característico "hombro" (shoulder) en el caso de rangos de dosis menores y con una progresión exponencial lineal y logarítmica a mayores dosis. A menores dosis existe un mayor potencial de reparación del DNA, del daño subletal y así la capacidad intrínseca de reparación del DNA específico irradiado determinará la inicial inclinación de la curva. La quimioterapia por su parte puede causar inhibición de la reparación del daño subletal e incluso de la reparación del daño letal, estando implicado de hecho esta función. Este proceso funcional de reparación se refiere a la reparación de las roturas simples o dobles de las cadenas de DNA, que se inician incluso en las primeras horas tras la irradiación. La radioterapia a su vez puede también inhibir el proceso de reparación celular activado tras la administración de la quimioterapia ${ }^{4}$.

Otros importantes componentes de la irradiación fraccionada incluyen los llamados fenómenos de repoblación, redistribución y reoxigenación. El primero, la repoblación, resulta de la división celular continuada que incluso en algunos modelos tumorales experimentales ha demostrado que se acelera después de 2 ó 3 semanas de tratamiento. La redistribución ocurre debido a la diferente sensibilidad de las células tumorales dependiendo de la fase del ciclo celular, que puede conducir a un reclutamiento de células más allá de la fase de reposo (GO). Un ejemplo sería la importancia de un quimioterápico que bloqueara la fase $\mathrm{Gl} / \mathrm{S}$, con lo cual se produciría acumulación de células, en una fase radiosensible del ciclo, potenciando así el efecto antitumoral total. También por este mecanismo se puede inducir la reducción de la proliferación acelerada causando así un efecto de potenciación de la irradiación.

El mecanismo de reoxigenación se cree que probablemente estará causado en parte por la pérdida de células tumorales y por la mejora del aporte vascular de las células hipóxicas agudas y crónicas. La quimioterapia puede alterar la proporción de células oxigenadas dentro del campo de radioterapia y de esta forma actuar positivamente en su efectividad. Por su parte la radioterapia, si se da antes de la quimioterapia, causa una mejora en el aporte vascular, por consiguiente en la distribución de la droga citotóxica en una determinada área.

Estos conceptos son algunos de los mecanismos que forman las bases teóricas de las interacciones de quimioterapia y radioterapia. Además muchos otros factores complican e influencian en estos mecanismos, en mayor o menor grado, dependiendo del tipo de quimioterapia o combinaciones de éstas, dosis, formas de administración, esquema de fraccionamiento de radioterapia, dosis por fracción, dosis total, tasa de dosis, o "timing" de la quimioradioterapia.

\section{Respuesta tumoral en relación a la dosis de radioterapia administrada}

Las curvas de supervivencia tumoral a la radioterapia son de forma parecida en diferentes tumores y tejidos. El hombro, como se ha señalado anteriormente, está en el menor rango de dosis y expresa así la habilidad de las células de reparar el daño subletal. Cuando la radioterapia se adminis- tra de forma fraccionada, este fenómeno ayuda a incrementar el índice terapéutico a causa de la diferencia intrínseca de la capacidad de reparación del daño subletal entre los tejidos sanos y el tumor. A lo largo de los años se han propuesto una serie de modelos matemáticos, y actualmente el que está más aceptado es el modelo lineal cuadrático. Este modelo sigue la teoría de que si la irradiación causa una simple y letal rotura de la doble cadena cromosómica (interacción lineal o alfa), o si causa una lesión subletal, con rotura parcial de la doble cadena, en este caso, se requerirá más de una para que se produzca la muerte celular (componente beta o cuadrático). Experimentalmente, en curvas de supervivencia de la inmensa mayoría de los tejidos no tumorales, se evidencia que, básicamente, existen dos tipos de respuesta a nivel tisular: temprana y tardía. Estos tejidos de respuesta rápida o temprana, como la piel, la médula espinal, la mucosa gastrointestinal, se da en tejidos de rápido recambio celular (rapid cell turnover), mientras que los de respuesta tardía, como el sistema nervioso central, el riñón o el mismo pulmón, presentan una tasa de recambio celular casi normal. Por su parte los tejidos tumorales parecen responder más como tejidos normales de respuesta aguda. El efecto de aumentar la dosis a nivel tumoral y en los diferentes tipos de tejidos normales o sanos será de interés si los potenciales efectos terapéuticos del tratamiento combinado son optimizados.

La relación de respuesta a una dosis determinada de irradiación está bien establecida documentalmente. A partir de aquí se plantea la posibilidad de obtener mayor beneficio antitumoral mediante el aumento de las dosis más allá de lo considerado como dosis estándar. La dosis estándar representa la mayor y más efectiva dosis que puede llegar a administrarse dentro del contexto de una toxicidad tisular, en tejidos sanos, aceptable.

Los caminos probables de escalar las dosis de radiación a nivel de tumor, preservando los tejidos normales, podrían ser utilizando métodos basados en las técnicas de conformación (3-D), aplicando in vivo moduladores (como los radiosensibilizantes y radioprotectores), o finalmente mediante alteraciones del fraccionamiento. El desarrollo actual de los esquemas de alteración del fraccionamiento clásico (diferente de administrar una dosis diaria entre 1,8 y 2 Gy), se basan en datos radiobiológicos (tanto clínicos como de laboratorio), y sugieren diferentes caminos para incrementar el diferencial entre la respuesta tumoral y la de los tejidos sanos circundantes. En el esquema hiperfraccionado, el número total de fracciones se incrementa sin aumentar la duración total del tratamiento, permitiendo un aumento de la dosis total pero precisando la reducción de la dosis por fracción para actuar sobre el aumento de la toxicidad aguda. En los esquemas de fraccionamiento acelerado, la duración total del tratamiento se acorta, mientras que tanto la dosis total, el número de fracciones, y la dosis por fracción no sufren cambio o apenas una ligera reducción. Todos estos factores radioterápicos son importantes cuando se considera la administración concurrente de la quimioterapia.

\section{Respuesta tumoral a la dosis de quimioterapia administrada}

Las curvas de supervivencia para los agentes quimioterápicos varía ampliamente en los diferentes tejidos. Esto tam- 
bién puede variar dependiendo de la dosis del agente, si se administra solo o en combinación, o si sólo se administra una vez o en varias ocasiones. Si se administra en múltiples ocasiones, tanto el intervalo de tiempo como las dosis de los quimioterápicos administrados, más cualquier posible interacción añadida como podría ser la radioterapia, influenciaran la respuesta final total. Además, las propiedades farmacológicas de las drogas citotóxicas serán de extrema importancia en determinar la biodisponibilidad, que en ocasiones puede verse alterada a nivel tumoral como consecuencia de factores como la heterogeneicidad del flujo sanguíneo normal.

Existe suficiente evidencia científica que apoye la teoría que el aumento de la dosis de quimioterapia conduce a un aumento de la respuesta tumoral. Por esta razón se han propuesto, principalmente, dos categorías diferentes de aumento o escalada de dosis. Por una parte tenemos una curva de supervivencia cuyos niveles disminuyen en el rango mayor (por ejemplo los alcaloides de la vinca y el methotrexate), y por otra la curva de dosis respuesta clásica, logarítmica-lineal, que continua de manera indefinida (por ejemplo con los agentes alquilantes). En los últimos años, el principal factor limitante para estos últimos agentes, que sería la médula ósea, ha sido parcialmente soslayado mediante el desarrollo de factores de soporte hematológico. No obstante aún existen otras localizaciones como la gastrointestinal, la pulmonar - la neurológica, entre otras, que continúan representado una barrera, a nivel de toxicidad limitante, a cualquier aumento de dosis. Por otra parte los lugares considerados como santuarios, como a nivel del sistema nervioso central, o también la resistencia a los agentes quimioterápicos implican otras posibles causas del fallo de la quimioterapia que no parecen, actualmente, poderse solucionar con el aumento de dosis.

\section{Estrategias de radioquimioterapia}

La mejor manera de integrar radioterapia y quimioterapia continua siendo el objeto de estudios tanto a nivel de laboratorio como a nivel clínico. Se conoce, por ejemplo, que diferentes tipos de tumores tienen distintos niveles intrínsecos de radio y quimio sensibilidad ${ }^{4}$. Incluso dentro de una misma histología, a menudo existe una población heterogénea de células. Además, es importante recordar que incluso en similares grupos de pacientes, con similares estadios de la enfermedad, aún existen diferencias, particularmente en como toleran regímenes combinados. No obstante es factible construir modelos, basados en factores como la probabilidad de resistencia y carga tumoral, para ayudar en el intento de predecir la mejor combinación de tratamientos, dosis y "timming" que puedan mostrarse como superiores. Es importante desarrollar estas estrategias teóricas, aunque aún necesitan que sean llevadas a cabo bajo condiciones estrictamente controladas. Mediante los resultados de estudios clínicos aleatorizados se podrá definir de forma adecuado su lugar en la práctica clínica.

Un camino para intentar superar este problema es combinar agentes quimioterápicos que entre si, o junto a la radioterapia, no sumen toxicidades en el mismo tejido o lugar. $\mathrm{Di}$ versos estudios han indicado que cuando se compara la quimioterapia neoadyuvante o la adyuvante con la concurrente, en relación a la radioterapia, esta última ha mostrado ser mejor en relación a la respuesta tumoral ${ }^{5}$. Así la principal ventaja del tratamiento combinado concurrente sería el potencial de conseguir la máxima muerte celular tumoral en el menor período de tiempo. La intención de conseguir la disminución de la masa tumoral se basa en la bien documentada relación entre la masa tumoral y la probable curación de las distintas neoplasias. Así las razones que la mayor minimización de la carga tumoral se deba producir en el menor período de tiempo pueden ser variadas; la historia natural de los tumores experimentales, en función del tiempo, se caracterizan por un incremento del tamaño tumoral, el desarrollo de poblaciones tumorales quimio y radioresistentes y un incremento de la tasa de fenotipos metastásicos (según las hipótesis, tanto las mutacionales como las nomutacionales, del proceso metastásico). Goldie et al, basándose en la teoría de la mutación somática propuso una estrategia de combinar quimioterápicos sin resistencias cruzadas en esquemas de tratamiento alternantes ${ }^{6}$. Por otra parte el trabajo de Hill et al sugiere que los tumores alcanzan un tamaño crítico de tumor previamente a "explotar" generando fenotipos metastásicos ${ }^{7}$. Goldie et al consideran el desarrollo de tales fenotipos, como mutaciones análogas a las de resistencia tumoral a la quimioterapia o a la radioterapia, a partir que el tumor ha alcanzado un tamaño umbral o crítico ${ }^{8}$. En el escenario de origen no mutante, la variante mutante podría, progresivamente, incrementar su número. En cualquier caso, de acuerdo con la hipótesis de Goldie-Coldman, la necesidad prioritaria de conseguir el máximo de destrucción tumoral en el mínimo período de tiempo se basa en evitar el desarrollo tanto de los fenotipos metastásicos como los de resistencia a la radioquimioterapia. El uso concurrente de la quimioterapia y la radioterapia responde plenamente al aspecto dual de esta necesidad.

En otra hipótesis, la de Norton-Simon, se establece que la tasa de regresión tumoral se relaciona directamente a la dosis de quimioterapia y radioterapia y a la tasa de crecimiento tumoral previamente a cualquier tratamiento?. Por tanto, en un tumor heterogéneo, las clonas de células de crecimiento más lento deben ser menos numerosas y más resistentes que aquellas de crecimiento más rápido. En concordancia a la "regla de la peor droga" de Day et al, el quimioterápico peor o menos efectivo debe usarse desde un principio y durante cierto período de tiempo para eliminar o reducir los clones de crecimiento más rápido y que son relativamente más sensibles. Por su parte el citotóxico más efectivo puede ser de más utilidad, posteriormente, eliminado las clonas de crecimiento más lento y radioresistente ${ }^{10}$.

\section{La radioquimioterapia concurrente en el cáncer de pulmón eficacia y toxicidad}

En relación al tema de la toxicidad, aunque parece que no exista de una forma clara una suma de toxicidades es evidente que los regímenes de radioquimioterapia causan mayor toxicidad que la quimioterapia sola. Probablemente este incremento en toxicidad se produce principalmente a nivel hematológico, esofágico y pulmonar. El adecuado control de dichas toxicidades, mediante medidas activas o tratamientos de soporte serán de importancia, no sólo para mejo- 


\section{F. Casas y cols.}

rar la calidad de vida de los pacientes durante el tratamiento sino también para evitar interrupciones del tratamiento que pueden causar una disminución de la supervivencia, como ha señalado algún autor, en el tratamiento combinado del cáncer de pulmón de célula pequeña ${ }^{11}$.

\section{Toxicidad hematológica}

La mortalidad de las células tumorales tras la quimioradioterapia, administradas de manera individual o concurrente, es dosis dependiente. Así también la agresión a la médula ósea, que se expresa mediante una disminución de las células sanguíneas circulantes, es frecuentemente la principal toxicidad dosis-limitante debido a los riesgos de anemia sangrado e infección que comporta. Las estrategias destinadas a proteger a las células hemáticas hematopoyéticas o al estroma de la médula ósea de la muerte inducida por el tratamiento, el acelerar la hematopoyesis tras dicho tratamiento, teóricamente, pueden permitir tratamientos más intensivos sin los riesgos asociados comentados anteriormente. Pero para conocer el verdadero impacto del tratamiento combinado, también para poder incidir sobre él, debe conocerse al máximo la estructura y función de la médula ósea como órgano. Podemos empezar diciendo que las células madre pluripotentes (pluripotent stem cell) se replican y diferencian en líneas linfoides o mieloides a través de un complicado proceso regulado por una red de factores de crecimiento hematopoyéticos e interacciones celulares. La cascada a través de la diferenciación mieloide conduce a los eritrocitos, plaquetas, granulocitos y macrófagos, mientras que la linfoide conduce a las células T y B. Se han identificado familias enteras de factores de crecimiento (o citoquinas), que controlan estos procesos de replicación y diferenciación. Las células progenitoras hematopoyéticas y su prole se hallan envueltas en un estroma de células endoteliales, células adventicias, fibroblastos, macrófagos y células grasas en el seno de la médula ósea. Este medio microscópico es a la vez soporte físico y director en el desarrollo del proceso replicativo. Así no sólo el estroma responde a los factores de crecimiento secretados sino que también las celdillas geométricas formadas en el seno de dicho estroma mantienen un estrecho contacto entre los progenitores y su prole. De esta manera la diferenciación especifica de cada línea celular ocurre en esas celdillas como consecuencia del medio bioquímico definido por proteinas de la matriz extracelular específica.

También la distribución geográfica de la médula ósea es particularmente relevante para conocer los posibles efectos locales de la radioterapia. Las localizaciones más funcionales e importantes son la pelvis y las vértebras, y también las costillas, el esternón, el cráneo, la escápula y las porciones proximales de fémures y húmeros. Además ha de tenerse en cuenta que la disfunción de la médula ósea, en el caso de los procesos neoplásicos puede tener diversas etiologías.

1. Depleción o lesión directa de las células madre hematopoyéticas

2. Daño funcional o estructural del estroma o de la microcirculación.

3. Lesión de otras células colaboradoras que tienen una función reguladora o de hemostasis.

4. Perturbación directa de la función de la médula ósea por la enfermedad subyacente.
5. Un efecto inherente en las células madre de la médula ósea como consecuencia también de la enfermedad neoplásica subyacente.

Estas diversas agresiones producen una alteración en la producción y liberación de factores de crecimiento y en la sincronización final entre las interacciones intercelulares básicas en la función medular. Por esta razón la regulación del proceso de hematopoyesis se altera. De esta manera las consecuencias, agudas y crónicas, de la agresión del tratamiento citotóxico a la médula deben entenderse dentro del contexto de los mecanismos enumerados anteriormente. No obstante, puede ser muy difícil dilucidar cuales son las variables más importantes debido a las limitaciones en la evaluación tanto de la estructura como de la función de la médula. La determinación periférica de las células sanguíneas falla en demostrar la verdadera extensión de la supresión medular o su capacidad de tolerar terapia citotóxica adicional, debido principalmente a la capacidad de la médula ósea de compensar, transitoriamente la agresión. Tanto los cultivos de células progenitoras, el estudio histopatológico (aspirado y biopsia de la médula ósea), determinados radiosótopos o cultivos de células estromales pueden ser usados para evaluar varios aspectos cuantitativos y funcionales de la médula ósea aunque con una limitada visión. Es especialmente escasa o marginal su utilidad para demostrar efectos de la irradiación debido a factores como el volumen o la dosis. Probablemente el número de células maduras hematopoyéticas será el resultante tanto del incremento de la amplificación del ciclo de las células madre como de la capacidad de responder de la médula ósea, a largo plazo, a la agresión producida.

Las manifestaciones agudas de la toxicidad hematológica son conocidas por el clínico ya que la depresión de cada línea celular puede condicionar, de manera potencial, riesgos y problemas en los pacientes:

1. La granulocitopenia severa o neutropenia, se considera en pacientes en los cuales se obtiene una fórmula con un número absoluto de granulocitos (células polimorfonucleares o bandas) menores de 500 y presentan un riesgo substancial de infección. Entre 500 y 1000 se considera una neutropenia moderadamenre severa y a partir de aquí la mayoría de los pacientes toleran ligeros niveles de neutropenia.

2. La trombocitopenia se ha definido como una disminución en número por debajo de 140.000, aunque las manifestaciones clínicas de petequias o sangrado de mucosas raramente ocurre con valores de 100.000, salvo que desciendan por debajo de 20.000. Una complicación importante como es el sangrado intracraneal ocurre por debajo de 10.000 unidades.

3. La anemia aunque puede llegar a tolerarse relativamente bien incluso con niveles de hematocrito cercanos al $30 \%$, produce un impacto considerable en la calidad de vida del paciente e incluso puede llegar a comprometer la efectividad del tratamiento antineoplásico como posteriormente comentaremos.

Las manifestaciones tardías o crónicas en respuesta al tratamiento antineoplásico son menos conocidas, aunque el sistema hematopoyético parece recuperarse relativamente pronto tras quimioterapia o radioterapia. No obstante se sa- 
be que en pacientes multitratados, se produce una reducción en la tolerancia a la adición de otros tratamientos, mostrando menores nadires en las células sanguíneas periféricas.

La toxicidad aguda a la quimioterapia, con supresión de la médula ósea, es un efecto conocido y esperado y el grado de toxicidad varía en relación al tipo y a la dosis administrada, variando también la inmunosupresión. Normalmente el cisplatino, base del tratamiento actual del cáncer de pulmón de célula pequeña, muestra un nivel medio de mielosupresión, con un nadir a los 14 días y una recuperación aproximada de la médula ósea de 21 días.

La medula ósea también es extremadamente radiosensible. La fórmula sanguínea disminuye en número de forma aguda y progresivamente debido a la destrucción conjunta, tanto de las células maduras como de las progenitoras. La secuencia y grado de disminución son similares a las causadas por la mayoría de los agentes quimioterápicos, que reflejan la cinética de producción, maduración, longevidad y reserva de la médula ósea. Tanto las dosis de radiación, su tasa y el volumen de tratamiento, serán de importancia.

Repetiremos que las estrategias terapéuticas para combinar quimioterapia y radioterapia se basan tanto en lograr la erradicación del tumor como en consideran las toxicidades limitantes, en este caso, a nivel de la médula ósea. Las interacciones observadas se basan en los mecanismos comentados anteriormente, aunque no se puede decir que sean plenamente conocidos. La complejidad de estas interacciones fueron primeramente estudiadas por Kovacs et al haciendo hincapié en las alteraciones de la reserva hematopoyética que sigue a la administración de radioterapia y de diferentes agentes quimioterápicos ${ }^{12}$. En conjunto los datos muestran que la selectividad de las drogas para diferentes poblaciones de células hematopoyéticas determinan las consecuencias temporales de la tolerancia de la médula a la radiación tras la quimioterapia. Además han de tenerse en cuenta otras consideraciones adicionales en relación a la cinética de recambio celular tras el tratamiento citotóxico. Así la irradiación de pequeños volúmenes tras la quimioterapia seguramente será bien tolerado dado que las áreas no irradiadas actuarán compensando este déficit con un aumento de producción.

En resumen la toxicidad de la radioquimioterapia causa diversos grados de leucopenia, anemia y trombocitopenia. En las dos últimas décadas se han producido avances en el conocimiento de la fisiología de la hematopoyesis que han conducido al descubrimiento de factores de crecimiento hematopoyético que se están utilizando para el tratamiento de la toxicidad producida por los tratamientos combinados a nivel de médula ósea. Son glicoproteinas que estimulan la producción de células progenitoras mieloides que como consecuencia producen elementos mieloides maduros. La finalidad de estos factores ha sido reducir la duración y la intensidad de la neutropenia asociada a la quimioterapia, permitir la administración de la quimioterapia planificada inicialmente, incrementar las dosis de quimioterapia y/o reducir el intervalo de tiempo entre cada ciclo de tratamiento. Así estas substancias han sido utilizadas en estudios aleatorizados como soporte o para aumentar la intensidad de dosis de los regímenes de quimioterapia. La revisión sistemática de la literatura, de 12 estudios aleatorizados que incluían 2107 pacientes, para evaluar la efectividad de los factores estimulantes de colonias (de granulocitos o G-CSF y de granulocitos-macrofagos o
GM-CSF), en el tratamiento del cáncer de pulmón de célula pequeña, a nivel de supervivencia, tasa de respuesta, toxicidad y frecuencia de infección o de fiebre neutropénica ha llegado a la conclusión que la administración de G-CSF o GMCSF, destinada a mantener o a incrementar la dosis intensidad de quimioterapia planificada, no ha demostrado su efectividad en términos de mejor tasa de respuesta y de supervivencia. Además se ha observado un efecto perjudicial del uso de esta citoquina en pacientes con estadio intratorácico que habían sido tratados de manera concomintante con quimioterapia y radioterapia así como en estadios extratorácicos tratados con quimioterapia a altas dosis ${ }^{13}$. Incluso la American Society of Clinical Oncology (ASCO), ya en 1996 recomendaba que debía evitarse el uso de CSF en pacientes que recibieran quimioterapia y radioterapia concomitante, para puntualizar en el año 2000 que debía ser evitado su uso en pacientes en radioquimioterapia si se irradiaba el mediastino ${ }^{14}$, como sería el caso que nos ocupa.

También se ha estudiado el impacto del uso profiláctico de antibióticos para evitar o reducir la leucopenia febril . Cabe destacar especialmente un trabajo aleatorizado de la EORTC que concluye que el usos profiláctico del ciprofloxacino más la roxitromicina durante la administración de quimioterapia $^{15}$, reduce la incidencia de fiebre leucopénica, el número de infecciones, el uso de antibióticos y hospitalizaciones debido a dicha fiebre en un $50 \%$ y también una reducción en la muerte de causa infecciosa.

En relación a la anemia recordaremos que a menudo complica la evolución de la enfermedad neoplásica. Su etiología es multifactorial e incluye la ausencia de una apropiada producción de eritropoyetina en respuesta a la alteración de los niveles normales de hemoglobina ${ }^{16}$. Esta anomalía en la producción de eritropoyetina en pacientes anémicos es además exacerbada por la quimioterapia ${ }^{17}$. Por otra parte la eritropoyetina humana recombinada ( $\left.r-\mathrm{Hu}_{\mathrm{u}} \mathrm{EPO}\right)$ ha sido utilizada de manera satisfactoria para mejorar la anemia de los pacientes con cáncer, observándose un aumento del número de progenitores eritroides tanto en la médula ósea como en la sangre periférica en aquellos pacientes que reciben concomitantemente $r-H_{u}-E P O$ junto a quimioterapia ${ }^{18}$. Por otra parte se ha demostrado que la probabilidad de control tumoral en algunos cánceres tratados con radioterapia se asocia con los niveles de hemoglobina. Por ejemplo se ha demostrado en pacientes con tumores de cabeza y cuello, o cerviz, un valor predictivo de la hemoglobina en la supervivencia. Así se ha observado que las tasas de recidiva tumoral a nivel locoregional aumenta en pacientes anémicos y que tras la correción de la anemia el control local del tumor y la supervivencia pueden mejorar ${ }^{19}$. También se ha demostrado recientemente, de forma experimental en tumores desarrollados en ratones desnudos, que la administración de eritropoyetina restituye la radiosensibilidad de dichos tumores que se había reducido en situaciones de anemia ${ }^{20}$.

A nivel de cáncer de pulmón en general, en los últimos años, diversos artículos se han referido al recién comentado impacto de los niveles de hemoglobina en el control local y en la supervivencia. Destacaremos especialmente, en primer lugar, un metaanálisis de Caro et al que buscaba determinar si la anemia era un factor independiente pronóstico de supervivencia en pacientes con distintos tipos de cáncer. En relación a los pacientes con cáncer de pulmón que estaban anémicos, concluyó que, en éstos, el riesgo relativo de muer- 


\section{F. Casas y cols.}

te se incrementaba por un factor de 1,921. En este mismo contexto de pacientes en riesgo se expresa el segundo punto del resumen de las recomendaciones de la ASCO sobre el uso de la eritropoyetina ${ }^{22}$. Así si la administración de eritropoyetina es recomendada, con un nivel de videncia II, en pacientes con anemia tras la quimioterapia y una concentración de hemoglobina cercana da $10 \mathrm{~g} / \mathrm{dL}$, también se contempla con el mismo nivel de evidencia II la recomendación de su uso en pacientes con niveles basales de hemoglobina entre 10 y $12 \mathrm{~g} / \mathrm{dL}$, basándose en el juicio clínico o en la premisa que pacientes con comorbilidad específica tengan una mayor probabilidad absoluta de anemia o de mayor riesgo de efectos adversos relacionados con este grado de anemia que en otros pacientes con estas mismas concentraciones de hemoglobina. La ASCO en sus recomendaciones añade que como ejemplo de pacientes que pueden ser considerados para el uso de la eritropoyetina, se incluyen, entre otros, individuos ancianos con limitada reserva cardiopulmonar o pacientes con enfermedad coronaria y angina sintomática. Desde nuestro punto de vista existen datos clínicos objetivos que los pacientes afectos de cáncer de pulmón, enfermedad asociada al tabaco y a patología comórbida pulmonar y cardiaca, en tratamientos intensivos de quimioradioterapia como es el caso específico del CPCP también deben formar parte de este grupo. Así un estudio de Casas et $a^{23}$, en un grupo de pacientes afectos de cáncer de pulmón en tratamientos concurrentes de quimioradioterapia tras quimioterapia de inducción, 11 de célula pequeña forma limitada y 40 de célula no pequeña) estudió el impacto del uso de la eritropoyetina en el mantenimiento del karnofsky y de los niveles de hemoglobina. Además de constatar un impacto beneficioso y significativo de la administración de eritropoyetina a nivel del estado general y de los niveles de hemoglobina también constata como factor pronóstico significativo de supervivencia en el estudio multivariado, junto a factores clásicos como la pérdida de peso, la mejora final de la hemoglobina, la histología de cáncer de pulmón de células pequeñas y finalmente niveles de hemoglobina antes del tratamiento quimioradioterápico concurrente, mayores a 10 $\mathrm{g} / \mathrm{dL}$. En otro estudio de Choy et $\mathrm{al}^{24}$, analizando el impacto de los niveles de hemoglobina de grupos de pacientes con cáncer de pulmón tratados en protocolos de la RTOG también se encuentra una relación entre niveles de hemoglobina y supervivencia. Y finalmente un trabajo de Robnett et $a^{25}$ muestra una relación significativa entre los niveles de la hemoglobina en pacientes que han recibido tratamientos concurrentes de quimioradioterapia de inducción y la respuesta histológica a nivel de la pieza quirúrgica.

En relación a la trombopenia, la thrombopoetina, el factor sintetizado para la estimulación de esta serie, en base a evitar problemas hemorrágicos tras quimioterapia mielosupresiva aún esta en una fase de evaluación y de implementación clínica $^{26}$.

\section{Toxicidad esofágica}

El esófago, normalmente, está dentro del campo de irradiación de los pacientes con cáncer de pulmón y el daño agudo de su mucosa puede iniciarse a los pocos días de haber iniciado la irradiación. El rápido recambio celular de las células mucosas del esófago sano hace a este órgano parti- cularmente sensible al daño inducido por la radiación que en un principio se manifiesta como una respuesta inflamatoria. Si la tasa de repoblación de la capa celular epitelial basal sufre una agresión suficientemente importante, tras dicha inflamación se produce una denudación que provocará una atrofia de la mucosa y su ulceración $(40,1)$.

Entre estos pacientes, los hallazgos endoscópicos que se producen son un eritema de la mucosa, edema y en ocasiones la mucosa del esófago se convierte en friable. Microscópicamente, la capa epitelial del esófago muestra acantosis, atrofia, disminución de la actividad mitótica basal, queratosis, paraqueratosis, displasia y vacuolización citoplasmática. No obstante, como señala Jatoi et $a^{27}$, aunque algunos pacientes presenten síntomas de esofagitis, como la disfagia, no todos presentan hallazgos endoscópicos o histológicos que sugieran dicha esofagitis.

Cuando se administra radioterapia fraccionada se puede observar, entre los 20 y $30 \mathrm{~Gy}$, cierto grado de esofagitis aguda, cuyos síntomas se resuelven fácilmente en 7-10 días, que raramente será severa con menos de $50 \mathrm{~Gy}$. A partir de unos $60 \mathrm{~Gy}$, dependiendo también del tamaño de esófago irradiado, pueden aparecer problemas de estenosis. Teniendo en cuenta también que los problemas crónicos o de estenosis a este nivel, utilizando menores dosis que las señaladas pueden aparecer en esquemas acelerados de administración de la irradiación. Por su parte los agentes quimioterápicos pueden alterar de forma significativa la tolerancia del tejido esofágico irradiado y la incidencia de esofagitis severa puede aumentar hasta cerca del $50 \%$ en algunas series ${ }^{28}$. Un estudio con 105 pacientes afectos de cáncer de pulmón examinó los factores predictivos potenciales de una esofagitis severa. El uso de la quimioterapia concomitante fue uno de los más importantes. Los pacientes que recibieron quimioterapia concomitante e irradiación experimentaron mayor grado de esofagitis así como una mayor duración ${ }^{29}$.

En el caso del cáncer de pulmón de células pequeñas, en el cual el tratamiento quimoterápico concurrente con radioterapia hiperfraccionada parece ser el tratamiento de elección, el manejo de la esofagitis constituye un reto para el clínico tanto para conseguir administrar la totalidad del tratamiento planificado como para mantener la calidad de vida del paciente durante este tratamiento. Se ha evaluado en distintos estudios la incidencia, severidad, así como factores predictivos de la toxicidad, tanto aguda como crónica esofágica en pacientes afectos de cáncer de pulmón (tanto de célula pequeña como de célula no pequeña), en tratamientos combinados de radioquimioterapia. Mientras algunos señalan tanto el porcentaje de volumen tratado con más de 50 Gy como el porcentaje máximo de la circunferencia que ha recibido más de 80 Gy como factores predictivos de toxicidad tardía $^{30}$, otros señalan a la concomitancia con quimioterapia y la radioterapia hiperfraccionada, especialmente si ambas se administran juntas, como los factores más importantes tanto en la esofagitis aguda como en su mayor duración ${ }^{31}$. Ambos estudios coinciden que la longitud de esófago incluido en el campo de tratamiento no se muestra como factor predictivo de toxicidad aguda. Aunque en ambos trabajos la proporción de cánceres de pulmón de célula pequeña es limitada, sus resultados, especialmente en referencia al segundo artículo, coinciden con el mayor grado de esofagitis reportado por Turrisi et al en el brazo de radioquimioterapia hiperfrac- 
cionada concurrente en relación al que utilizó radioterapia con un fraccionamiento clásico. En nuestra experiencia en el tratamiento concurrente y hiperfraccionado del cáncer de pulmón de célula pequeña (resultados no publicados) tanto el grado como la duración de la esofagitis mayor o igual a grado 3 estaría también relacionado con la leucopenia que produciría una disminución en la reparación de las mucosas, en este caso la esofágica. Así de los 15 pacientes de un total de 50 tratados, que presentaron una esofagitis igual o mayor a grado 3, lo presentaron en el contexto, o como primer síntoma, de una leucopenia intensa o una aplasia de las 3 series hematológicas. Esta misma correlación ha sido señalada por Choi et a ${ }^{32}$ aunque en casos de cáncer de pulmón de célula no pequeña, estadio IIIA, que habían sido sometidos a tratamientos de inducción preoperatoria con esquemas de quimioradioterapia concurrente hiperfraccionada. Observó un $14 \%$ de esofagitis grado 4 que normalmente coincidieron con el principio de una marcada leucopenia por la quimioterapia y que al recuperarse ésta se producía una recuperación de la disfagia.

Una posible vía de actuación o de profilaxis ante la esofagitis en el cáncer de pulmón de célula pequeña sería el uso de la amifostina dado que en la irradiación hiperfraccionada concurrente con quimioterapia dicha toxicidad esofágica es dosis limitante. No obstante un reciente estudio fase II, con 34 pacientes, tratados con amifostina y con el tratamiento combinado ahora comentado no ha logrado demostrar ningún beneficio en el control de la toxicidad a nivel del esófago $^{33}$, en contraposición a otros resultados positivos en el cáncer de pulmón de célula no pequeña ${ }^{34,35}$. Una de las razones esgrimidas es que probablemente la dosis o la pauta de administración de la amifostina no consiguen un efecto protector suficiente ante la agresión que significa la combinación de radioterapia hiperfraccionada y quimioterapia. No obstante en dicho estudio se han reproducido los resultados de control local y supervivencia alcanzados en publicaciones previas, mostrando así que la posible protección de tumor por la amifostina no parece existir.

Desde nuestro punto de vista, además de proseguir la investigación con radio y quimioprotectores y en los factores pronósticos de la esofagitis, que como hemos comentado es actualmente una toxicidad limitante en el tratamiento del $\mathrm{CPCP}$, se ha de considerar un tratamiento profiláctico o sintomático de esta eventualidad que además de alterar la calidad de vida del paciente produce una secundaria reducción de la ingesta y una perdida de peso que debilita al paciente y disminuye su estado general. Algunos autores ${ }^{36}$ defienden el uso profiláctico de antiácidos especialmente en pacientes con historia de úlcera gástrica y hernia de hiato dado que el reflujo gastroesofágico puede agravar una esofagitis subclínica incipiente. En nuestra práctica clínica (resultados no publicados), desde hace unos años, además de utilizar en estas contingencias antiácidos, antiinflamatorios o antifúngicos si se comprueba sobreinfeción por estos agentes patógenos, a partir de una esofagitis grado 2 y especialmente en la de grado 3, administramos Fentanilo transdermico (Durogesic), a dosis de 25 microgramos /72 que permite paliar al paciente el dolor y continuar una ingesta alimentaría, modificada pero suficiente, al mismo tiempo que monitorizamos de una forma muy cercana tanto su evolución clínica como la de la fórmula leucocitaría para detectar cualquier leucopenia intensa que nos llevaría al ingreso del paciente.

\section{Toxicidad pulmonar}

La tolerancia del tejido pulmonar normal impone limitaciones al tratamiento combinado en el cáncer de pulmón de célula pequeña ya que en estos pacientes, normalmente, se necesita irradiar considerables zonas del pulmón, a dosis relativamente altas, que pueden ocasionar secuelas a largo plazo. Estas secuelas conocidas como neumonitis y fibrosis continúan limitando el uso de la irradiación en el tratamiento del cáncer de pulmón.

En la practica clínica el oncólogo radioterapeuta acepta cierto daño estructural, sea neumonitis o fibrosis, debido a la amplia capacidad de reserva funcional del pulmón. Es decir, funcionalmente, el pulmón no verá alterado su funcionamiento aunque una pequeña parte sea destruido. A dicho nivel la morbilidad viene determinada por muchos factores, incluyendo el daño ocasionado en el tejido, el impacto de este daño en la función del órgano y finalmente el impacto de ambas lesiones en el estilo de vida de un paciente dado. Porque, como ya hemos comentado, debido a la capacidad de reserva del pulmón, el daño estructural no se verá necesariamente reflejado en forma de morbilidad clínica objetivable en la función pulmonar. Esta disociación entre daño y morbilidad a nivel pulmonar es un reflejo de la particular organización de las unidades anatómicas responsables de la función pulmonar.

La morbilidad sería un reflejo de dos parámetros:

(a) la supervivencia de un suficiente número de células para mantener la función del tejido y

(b) la organización de estas células en su unidad para llevar a cabo la función del tejido

La relación espacial entre estas unidades funcionales difiere entre tejidos y un determinante capital en la relación entre daño y cualquier morbilidad resultante. Anatómicamente el pulmón es un sistema de ductos, acompañados de vasos sanguíneos, y que terminan en el alveolo que es donde se produce el intercambio de gases. Pero, en verdad, el acino es la subunidad funcional del pulmón, con una estructura bien definida que empieza en las ramificaciones de los bronquiolos terminales a los respiratorios finalizando en el saco alveolar, cada uno de los cuales da lugar a numerosos alveolos. Cada acino es una única entidad independiente de su vecino. Así parece que la destrucción de un único acino no tiene un efecto medible en la normal función de un pulmón sano y que el daño funcional, reflejado particularmente en la función pulmonar total, se manifestará sólo cuando un número determinado de estas unidades es destruido. En la práctica clínica no obstante la radioterapia torácica se asocia con alteraciones significativas en la función pulmonar siendo medible mediante tests de función pulmonar $^{37}$, especialmente en pacientes con cáncer de pulmón que frecuentemente tienen compromiso en ése órgano previo al tratamiento secundario tanto a la neoplasia como a enfermedades pulmonares previas coexistentes. Se han reportado mayores niveles de declinación en las pruebas de funcionalismo pulmonar tras tratamientos combinados de radioterapia y quimioterapia comparados con radioterapia sola ${ }^{38}$ y además los regímenes de radioquimioterapia concurrente se han mostrado más tóxicos que los secuenciales. Se ha de tener en cuenta, además, que el pulmón sano es un tejido de respuesta lenta, en el cual el daño no se mani- 


\section{F. Casas y cols.}

fiesta hasta semanas o años tras la finalización del tratamiento a diferencia de los tejidos de respuesta aguda. Un análisis de estudios experimentales con ambos tipos de tejidos con respuesta aguda o tardía han demostrado que en estos últimos tejidos, como es el caso del pulmón, los aumentos de fraccionamiento serán más tóxicos ${ }^{39}$. En relación a la importancia del factor volumen como de importancia en el desarrollo de neumonitis tras la irradiación cabe destacar un estudio que muestra que el riesgo de ésta varía en relación con la zona irradiada, de la misma manera como se ha observado en la experimentación animal. Así en un grupo de 60 pacientes con cáncer de pulmón tratados con quimioradioterapia secuencial o concurrente, la zona de irradiación fue evaluada. Cuando se analizó el riesgo de neumonitis en relación a la exacta localización de la zona irradiada, se constató que cuando la base del pulmón se irradiaba la incidencia de neumonitis aumentaba de forma significativa en relación a otras localizaciones ${ }^{40}$. Algunos autores atribuyen este hecho a las diferencias en la cantidad e DNA de las células pulmonares en la base o en el ápex ${ }^{41}$. Por otra parte el advenimiento de la radioterapia conformada en 3 dimesiones (3-D) ha modificado totalmente la distribución de dosis de la planificación pulmonar. Actualmente los histogramas dosis -volumen (DVH) serán los que reflejen el impacto de los cambios en la función regional pulmonar y en la estructura funcional de todo el pulmón. Posteriormente estos histogramas pueden ser usados para desarrollar modelos matemáticos destinados a predecir la probabilidad de predecir complicaciones en los tejidos sanos (NTCP). Aunque el usos de estos modelos requieren una posterior confirmación clínica con muchos pacientes, complicando la cuestión el hecho que se administra de manera conjunta la quimioterapia. En un estudio holandés con 382 pacientes afectos de cáncer de mama, linfoma y cáncer de pulmón de células no pequeñas, irradiados en 2 centros distintos, se compararon diferentes modelos de NTCP a fin de predecir la incidencia de neumonitis en base a la distribución de la dosis en el pulmón. La conclusión fue que la dosis media pulmonar fue un factor predictivo de neumonitis de mayor importancia que el volumen de pulmón que recibía más de una determinada dosis ${ }^{42}$. No obstante dicho volumen, específicamente el V20 definido como el porcentaje de pulmón irradiado a más de 20Gy, también presenta un importante factor predictivo de neumonitis tras quimioradioterapia como muestra un estudio japonés con 71 pacientes afectos de cáncer de pulmón concluyó que un V20 < del $25 \%$ se asociaba con una baja incidencia de neumonitis grado 2 o mayor, mientras que una V20 >30\% se asociaba de manera significativa a una mayor incidencia de radioneumonistis grado 2 o superior ${ }^{43}$. Al mismo tiempo, otros autores señalan una muy estrecha correlación entre el V20 y la dosis media en pulmón ${ }^{44}$. Destacaremos también un reciente análisis de 32 pacientes con cáncer de pulmón de células no pequeñas (NSCLC) tratados con radioterapia hiperfraccionada acelerada continua (CHART), tras tratamiento quimioterápico de inducción. En este estudio se concluyó que este tipo de hiperfraccionamiento parece mostrar un mayor índice terapéutico que la radioterapia convencional en relación a la toxicidad pulmonar. Asimismo señalan al V20 y a la dosis media pulmonar como factores predictivos de utilidad para predecir el riesgo de radioneumonistis ${ }^{45}$. Aunque cabe destacar que en este estudio, a diferencia del previo del grupo japonés que calculaba el V20 excluyendo el volumen de traquea, bronquios y el del GTV, además de excluir del contorno pulmonar las vías aéreas para determinar dicho V20 se excluía el PTV. Inclusos algún otro autor sustrae al contorno pulmonar, además de traquea, bronquios y GTV, el diafragma para calcular el V3046. Esta divergencia en el cálculo de ésta variable puede explicar ciertas diferencias de resultados.

Por otra parte se ha demostrado experimentalmente en animales de laboratorio que mientras tras la radiación unos desarrollaran neumonitis otros pueden presentar fibrosis ${ }^{47}$. Ante esto se estudiaron 56 pacientes afectos de CPCP, forma limitada, tratados en dos estudios de quimioradioterapia con radioterapia convencional (45 Gy administrados en 25 sesiones durante 5 semanas) o con radioterapia hiperfraccionada acelerada (45 Gy en 30 sesiones, dos al dia, administradas en 3 semanas), hallando que el riesgo y severidad de la fibrosis, analizada radiográficamente mediante TAC, aumenta con la dosis total, con el tratamiento acelerado y también en relación con la heterogeneidad entre pacientes. Sugiriendo con esta última variable que el riesgo de fibrosis está fuertemente correlacionado con factores inherentes al paciente que pueden variar ampliamente entre cada individuo $^{48}$. Esta variabilidad en la respuesta del tejido normal puede utilizarse para individualizar estrategias de tratamiento. Así algún estudio muestra que el riesgo de formación de fibrosis en el pulmón tras la irradiación se correlaciona con los niveles de TGF-Beta en el suero ${ }^{49}$. Por esta razón se ha podido relacionar el riesgo de la toxicidad pulmonar sintomática radioinducida usando tanto parámetros físicos (V30), como parámetros biológicos (TGF- beta), y estratificar en función de ellos pacientes de bajo, medio y alto grado de desarrollar dicha toxicidad ${ }^{50}$. Incluso algún autor ha señalado el probable efecto predictor del TGF-beta para seleccionar pacientes con menor riesgo de toxicidad pulmonar en los cuales pueda administrarse mayores dosis dentro de programas de escalada de dosis. $(59,1)$

Probablemente, uno de los estudios más recientes para conocer los efectos de la radioterapia y la quimioterapia en la función pulmonar en pacientes con cáncer de pulmón es el publicado recientemente por el grupo del MD Anderson ${ }^{51}$. Aunque es un estudio basado exclusivamente en cáncer de pulmón de célula no pequeña muestra 5 grupos homogéneos de pacientes, que participaron en distintos protocolos de la RTOG o del propio Hospital, y que fueron tratados respectivamente con radioterapia exclusiva (19 pacientes), con quimioterapia secuencial y radioterapia estándar (24 pacientes), quimioterapia concurrente con radioterapia con fraccionamiento clásico, y finalmente con quimioterapia concurrente y radioterapia hiperfraccionada (27 pacientes) por lo que permite realizar analogías de toxicidad en el cáncer de célula pequeña que nos ocupa. Así se estudiaron factores como la capacidad pulmonar total (TLC) y la capacidad de difusión para el monóxido de carbono (DLCO), concluyendo que la adición de quimioterapia a la radioterapia aumenta de manera significativa la disminución de la TLC y de la DLCO que se producía tras la radioterapia sola. Y que el mayor descenso en DLCO sucede en pacientes en tratamiento concurrente de quimioradioterapia.

Concluyendo sobre la toxicidad pulmonar podemos decir que el pulmón es el órgano limitante o crítico de mayor importancia en el tratamiento quimioradioterápico del cáncer 
de pulmón. Se supone que se produce un daño celular inmediato tras la irradiación mediado por interacciones multicelulares de citoquinas con inducción y progresión de reacciones inflamatorias y de fibrosis en los tejidos. La pentoxifilina parece disminuir la producción de citoquinas proinflamatorias, particularmente del factor alfa de necrosis tumoral (TNF-alfa), en respuesta a estímulos dañinos y puede por otra parte proporcionar protección contra el daño celular mediado por citoquinas, producido por la iradiación. Rube et al, en un estudio experimental demuestra una relación significativa entre el aumento de TNF-alfa, inducido por la radiación, en el tejido pulmonar durante la fase de neumonitis. Observando también una reducción importante del TNF-alfa en el grupo de estudio que habían recibido pentoxifilina y radiación comparados con el grupo que había recibido irradiación de forma exclusiva ${ }^{52}$. Dada la importancia de este hecho, poder disponer de una medicación eficaz y que se puede administrar de manera profiláctica para evitar la neumonitis, son prioritarios otros estudios confirmatorios en este sentido.

\section{Otras toxicidades}

Entre otras toxicidades que se pueden encontrar en la irradiación concurrente del cáncer de pulmón como órgano crítico a nivel torácico se debe pensar en el corazón. Éste puede llegar a recibir una dosis de radiación no despreciable debido a la gran masa tumoral de la mayoría de los cánceres de pulmón. En general, ha sido descrito un ligero derrame pericárdico postirradiación relacionado tanto con la dosis, con el volumen de corazón irradiado como con la dosis por fracción administrada, que no acostumbra a tener trascendencia clínica ${ }^{53}$. Probablemente la medición exacta de la toxicidad que puede llegar a producir el tratamiento concurrente quimioradioterápico en el cáncer de pulmón podría determinarse mediante la monitorización de los niveles de la troponina cardiaca, marcador temprano de daño miocárdico, que ya se ha mostrado de utilidad en mostrar esta toxicidad subclínica tras quimioterapia a altas dosis $^{54}$.

Una toxicidad frecuente, que sin amenazar la vida del paciente si que parece alterar su calidad de vida es la neuropatía asociada al cisplatino. Se han postulado distintos tratamientos como los antidepresivos tricíclicos y la vitamina E. Si bien la nortriptilina, en un estudio randomizado no ha demostrado ningún beneficio ${ }^{55}$, la vitamina $\mathrm{E}(300 \mathrm{mg} / \mathrm{d})$, administrada de manera preventiva durante la quimioterapia con cisplatino, y posteriormente durante 3 meses más, disminuye la incidencia y severidad de la neuropatía periférica $^{56}$.

\section{La toxicidad del tratamiento del cáncer de pulmón en pacientes de edad avanzada}

Los pacientes ancianos, o de edad avanzada, son una parte considerable de la totalidad de los pacientes afectos de cáncer de pulmón. En este subgrupo siempre ha sido controvertido la importancia pronóstica del factor edad, especialmente en aquello que se refiere a la posibilidad de presentar mayor toxicidad ante un tratamiento a dosis plenas. En el año 2000 se publicó un análisis retrospectivo del estudio aleatorizado del Intergroup Trial 0096 sobre la supervivencia de pacientes afectos de cáncer de pulmón de célula pequeña en pacientes menores de 70 años o con 70 años y mayor edad. Este último subgrupo constituía el 13\% de los 381 pacientes en el estudio y no presentaron diferencias significativas respecto al resto del grupo en relación a la distribución por género, estado general y pérdida de peso. Se observó que tanto la toxicidad hematológica grado 4 y 5 así como la mortalidad fue significativamente mayor en el grupo de mayor edad. No existiendo, por otra parte, esta diferencia en otro tipo de toxicidad. En relación a la respuesta, mientras que no se detectaron diferencias significativas en relación a la tasa de respuesta, tasa de supervivencia libre de enfermedad, tiempo hasta la recidiva local, o duración de la respuesta, la supervivencia total fue mayor en pacientes menores de 70 años $(p=0,05)$. Se observó también que la diferencia en supervivencia según grupos de edad se producía en los primeros 6 meses del estudio. En las conclusiones señalaban que si bien los pacientes de 70 o más años presentaban similares tasas de respuesta y supervivencia, mostraban mayor grado de toxicidad hematológica, por lo que probablemente debían seleccionarse aquellos pacientes mayores con un buen estado general| ${ }^{57}$. Esta mayor toxicidad hematológica puede explicarse debido a que la concentración de células madre hematopoyéticas pluripotentes parece reducirse con la edad. Así se ha observado una reducción de dicha concentración en la médula ósea de personas mayores de 65 años con anemia, aunque no en personas más jóvenes. Ciertos hallazgos clínicos como un aumento de la incidencia y prevalencia de la anemia con la edad, una reducción de la respuesta de los reticulocitos en pacientes ancianos anémicos, un incremento de la mortalidad por infección y una reducción de la concentración de tejido hematopoyético con la edad, indican una disminución de la reserva de células madre hematopoyéticas pluripotentes ${ }^{58}$. Por otra parte como señalan Balducci et al ${ }^{59}$, actualmente la anemia se considera un parámetro de máxima importancia, ya que se asocia con una disminución de la calidad de vida y de los niveles de energía. Estos niveles parecen ser óptimos con concentraciones de hemoglobina entre 11 y $13 \mathrm{~g} / \mathrm{dL}$ ya que permiten una mayor autonomía en pacientes ancianos. Así la anemia en este subgrupo de pacientes además de producir una pérdida de esta independencia, de la calidad de vida, de la limitación de recibir algún otro tratamiento, puede asociarse también a una potenciación en la toxicidad de los quimioterápicos, ya que en esa situación la concentración del citostático puede aumentar y secundariamente su toxicidad $^{60}$. Por todas estas consideraciones Balducci señala la necesidad del uso preventivo de factores de crecimiento para prevenir la mortalidad precoz observada en pacientes ancianos que son tratados con regímenes con una toxicidad de dosis parecida al CHOP (el tratamiento quimioradioterápico del cáncer de pulmón de células pequeñas puede considerarse de una toxicidad igual o superior). También de mantener los niveles de hemoglobina aproximadamente en $12 \mathrm{~g} / \mathrm{dL}$ a fin de prevenir las complicaciones de la anemia y de la neutropenia y finalmente efectuar el ajuste de dosis de los cistostáticos de excreción renal de estos pacientes que son de riesgo de una toxicidad relacionada con la quimioterapia a causa de otros factores más allá de la edad ${ }^{61}$. 


\section{Tratamiento preventivo o de soporte ante la toxicidad tras la quimioradioterapia en el cáncer de pulmón}

Actualmente el tratamiento quimioradioterápico concurrente es el tratamiento de elección del cáncer de pulmón. Pero a pesar de una respuesta inicial al tratamiento sólo una pequeña minoría de todos estos pacientes vivirá más allá de 3 años. Su tendencia a la metastización justifica un tratamiento intensivo que no está exento de cierta toxicidad que se localiza principalmente a nivel de la médula ósea, del esófago y del tejido pulmonar sano. Las manifestaciones agudas de la toxicidad derivada del tratamiento en estos órganos críticos puede comprometer tanto la administración del tratamiento que se considera adecuado o más efectivo como la propia vida del paciente. Así ambas cosas, un tratamiento no suficientemente activo como la propia toxicidad convergen en una menor probabilidad de supervivencia. Como hemos comentado anteriormente los efectos agudos del tratamiento, a diferencia de los crónicos, pueden ser modificados o prevenidos a lo largo de la administración de éste. De esta forma surge el concepto del tratamiento preventivo o de soporte a la toxicidad que busca aumentar la tolerancia y la calidad de vida del paciente durante la terapéutica concurrente y lograr al fin una mayor supervivencia.

A nivel hematológico tanto la leucopenia como la anemia deben ser atentamente monitorizadas. Aunque en el primer caso parece que el uso profiláctico de factores estimulantes de colonias no ha demostrado aún una suficiente efectividad a nivel de conseguir una mayor supervivencia, tasa de respuesta, frecuencia de infección o fiebre neutropénica, y puede aumentar incluso la toxicidad del tratamiento si se administra de manera concomitante con la irradiación mediastínica. En cambio la administración profiláctica de antibióticos (ciprofloxacino más roxitromicina), si que se ha mostrado de utilidad en algunos de estos parámetros de evaluación, especialmente en la reducción de la muerte de causa infecciosa. En relación a la anemia coexisten diversos aspectos que la convierten en una toxicidad en la que es importante su corrección. En primer lugar está relacionada con la calidad de vida del paciente dado que su síntoma principal, la fatiga afecta de forma evidente el estado funcional del paciente. En segundo lugar, y no por ello de menor importancia, la anemia se ha demostrado como un factor pronóstico negativo tanto de supervivencia como de efectividad del tratamiento, especialmente en el caso de la radioterapia por razones radiobiológicas. Así diversos estudios, desde metaanálisis hasta estudios prospectivos, pasando por las recomendaciones de sociedades científicas como la ASCO, aconsejan su corrección, especialmente en tratamientos intensivos, en pacientes ancianos o con enfermedades crónicas importantes. En estos pacientes la eritropoyetina humana recombinada ( $r-\mathrm{Hu}$-EPO), especialmente la tipo alfa ha demostrado tanto su eficacia como su posible impacto en el estado funcional del paciente y probablemente en la supervivencia.

A nivel esofágico la toxicidad combinada de radioterapia y quimioterapia debe afrontarse tanto a nivel investigacional mediante una optimización de la planificación en 3-D o mediante IMRT, como con el uso de radio y quimioprotectores como la amifostina cuya efectividad muestra actualmente resultados esperanzadores aunque en ocasiones contradictorios. También es necesario estudiar de forma prospectiva su relación con la leucopenia intensa. Finalmente a este nivel se ha de tener en cuenta que la esofagitis, el dolor que provoca, limita y compromete la principal vía de alimentación del paciente y por tanto su nutrición. Debe prevenirse o tratarse su manifestación con anestésicos, antiinflamatorios, antiácidos antifúngicos o incluso morfina, especialmente según nuestra experiencia con fentanilo transdérmico, si fuera necesario.

A nivel pulmonar la neumonitis del tejido pulmonar sano debe prevenirse o tenerse en cuenta avanzando en el conocimiento sobre factores pronósticos de su aparición. Los histogramas dosis-volumen y especialmente el V20 u otros modelos matemáticos para predecir la probabilidad de toxicidad en tejidos sanos se han mostrado especialmente útiles en este sentido. También otros factores biológicos como el TGFbeta puede ser de utilidad para evaluar, durante el propio tratamiento y así poder prevenir, la aparición de toxicidad pulmonar. Recientemente estudios experimentales han demostrado cierto efecto protector de la pentoxifilina que debe demostrarse en estudios prospectivos aleatorizados.

\section{Bibliografía}

1. Rubin P. Radiation toxicology: quantitative radiation pathology for predicting effects. Cancer 1977; 39: 729-36.

2. Philips T, Fu K. The interaction of drug and radiation effects on normal tissues. Int Journal Radiat Oncol Biol Phys 1978; 4: 59-64.

3. Steel GG, Peckham MJ. Expoitable mechanisms in combined radiotherapy-chemotherap: the concept of additivity. Int J Rad Oncol Biol Phys 1975; 5: 85-90.

4. Carney DN, Mitchell JB, Kinsella TJ. In vitro radiation and chemotherapy sensitivity of established cell lives of human small cell lung cancer and its large cell morphologic variants. Cancer Res 1983; 43: 2806.

5. Munro AJ. An overview of randomised controlled trials of adjuvant chemotherapy in head and neck cancer. Br J Cancer 1997; 71: 83.

6. Goldie JH, ColdmanAJ, Gudauskas G. Rationale for the use of alternating non-cross-resistant chemotherapy. Cancer Treat Rep 1982; 66: 439.

7. Hill Rp, Chambers Af, Liug V, et al. Dynamic heterogeneity. Rapid generation of metastatic variance in mouse B-16 melanoma cells. Science 1984; 224: 2119.

8. Goldie JH. Scientific basis for adjuvant and primary (neoadjuvant) chemotherapy. Semin Oncol 1987; 14: 1.

9. Norton L, Simon R. Tumor size, sensitivity to therapy, and the design of treatment schedules. Cancer Treat rep 1977; 66: 439.

10. Norton L, Day R. Potential innovations in scheduling of cancer chemotherapy. In: Important Advances in Oncology 1991. De Vita VT, Hellman S, Rosenberg SA (Eds). Philadelphia, JB Lippincot 1991.

11. Videtic GM, Fung K, Tomiak AT, Stitt LW, Dar AR, Truong PT et al. Using treatment interruptions to palliate the toxicity from concurrent chemoradiation for limited small cell lung cancer decreases survival and disease control. Lung cancer 2001; 33: 249-58. 
12. Kovacs C, Evans M, Hooker J, Johnke R. Long-term consequences of chemotherapeutic agents on hematopoiesis: Development of altered radiation tolerance. $\mathrm{NCl}$ Monogr 1988; 45.

13. Berghmans $T$, PaesmansM, Lafitte JJ, Mascaux C, Meert AP, Sculier JP. Role of granulocyte and granulocyte-macrophage colony-stimulating factors in the treatment of small-cell cancer: a systematic review of the literature with metodological assessment and meta-analysis. Lung cancer 2002; 37: 11523.

14. Ozer H, Armitage JO, Bennet Ch L, Crawford J, Demetri GD, Pizzo PA et al. 2000 update of recomendations for the use of hematopoietic colony-stimulating factors: evidence-based, clinical practice guidelines. J Clin Oncol 2000; 18: 3558-85.

15. Tjan-Heijnen VC, Postmus PE, Ardizzoni A, Manegold $\mathrm{CH}$ Burghouts J, van Meerbeeck J et al. Reduction of chemotherapy-induced febrile leucopenia by prophylactic use of ciprofloxacin and roxithromycin in small-cell lung cancer patients: an EORTC double-blind placebo-controlled phase III study. Ann Oncol 2001; 12: 1359-68.

16. Miller CB, Jones RJ, Piantadosis S, et al. Decreased erythropoietin response in patients with the anemia of cancer. $N$ Engl J Med 1990; 322: 1689-92.

17. Schapira L, Antin JH, Ransil BJ, et al. Serum erythropoietin levels in patients receiving intensive chemotherapy and radiotherapy. Blood 1990; 76: 2354-9.

18. Ludwig $\mathrm{H}$, Fritz $\mathrm{E}$, Kotzmann $\mathrm{H}$, et al. Erythropoietin treatment in anemia associated with multiple myeloma. $\mathrm{N}$ Engl J Med 1990; 322: 1693-9.

19. Henke M, Guttenberg R, Barke A, et al. Erythropoietin for patients undergoing radiotherapy: A pilot study. Radiother Oncol 1999; 50: 185-90.

20. Stüben G, Pöttgen C, Knühmann K, Scmidt K, Stuscheke M Thews $O$, Vaupel P. Erythropoietin restores the anemia-induced redujction in radiosensitivity of experimental human tumors in nude mice. Int J Radiat Oncol Biol Phys 2003; 55: 1358-62.

21. Caro JJ, Salas M, Ward A, et al. Anemia as an independent prognostic factor for survival in patients with cancer: A systematic, quantitative review. Cancer 2000; 91: 2214-21.

22. Rizzo JD, Lichtin AE, Woolf SH, Seindenfeld J, Bennet $\mathrm{CH}$, Cella $D$, et al. Use of epoetin in patients with cancer: evidencebased clinical practice guidelines of the American Society of Clinical Oncology and the American Society of Hematology. J Clin Oncol 2002; 20: 4083-4107.

23. Casas F, Viñolas N, Ferrer F, Farrús B, Gimferrer JM, Agustí C, Belda J, Luburich P. Improvement in performance status after erythropoietin treatment in lung cancer patients undergoing concurrent chemoradiotherapy. Int J Radiat Oncol Biol Phys 2003; 55: 116-24.

24. MacRae Shyr $Y$, Johnson $D$, Choy $H$. Declining hemoglobin during chemoradio-therapy for locally advanced non-small cell lung cancer is significant.Radioat Oncol 2002; 64: 37-40.

25. Robnett TJ, Machtay M, Han S, Shager JB, Friedberg JS, Kaiser LR. Pathological response to preoperative chemoradiation worsens with anemia in non-small cell lung cancer patients. Cancer J 2002; 8: 263-7.

26. Vadhan-Rai S. Recombinant human thrombopoietin in myelosupreppresive chemotherapy. Oncology 2001; 15: 35-8.

27. Mascarenhas F, Silvestre ME, Sa da Costa M, et al. Acute secondary effects in the esophagus in patients undergoing radiotherapy for carcinoma of the lung. Am J Clin Oncol 1989:12:34-40.

28. Jatoi A, Thomas Ch R. Esophageal cancer and the esophagus : challenges and potential starategies for selective cytoprotection of the tumor-bearing organ during cancer treatment. Semin Radiat Oncol 2002; 12:62-7.

29. Choy H, La Porte K, Knill-Selby E, et al. Esophagitis in combined modality therapy for locally advanced non-small cell lung cancer.Semin Radiat Oncol 1999; 9:90-6.

30. Werner-Wasik M, Pequignot $E$, Leeper $D$, et al. Predictors of severe esophagitis include use of concurrent chemotherapy, but not hte length of irradiated esophagus :A multivariate analysis of patients with lung cancer treated with nonoperative therapy. Int J Radiat Oncol Biol Phys 2000; 48:689-96.

31. Maguire PD, Sibley Gs, Zhou SM, Jamieson TA, Ligh KL, Antonie PA et al. Clinical and dosimetric predictors of radiation-induced esophageal toxicity. Int J Radiat Oncol Biol Phys 1999; 45: 97-103.

32. Choi NC, Carey RW, Daly W, Mathisen D, Wain J, Wrigth C, et al. Potential impact on survival of improved tumor downstaging and resection rate by preoperative twice-daily radiation and concurrent chemotherapy in stage IIIA non-small-cell lung cancer. J Clin Oncol 1997; 15: 712-22.

33. Arquette M, Wasserman T, Govindan R, Garfield D, Senzer N, Gillenwater $\mathrm{H}$ et al. Phase II evaluation of amifostine as an esophagela mucosal protectant in the treatment of limited-stage small cell lung cancer with chemotherapy and twice-daily radiation. Semin Radiat Oncol 2002; 12: 59-61.

34. Antonadou D. Radiotherapy or chemotherapy followed by radiotherapy with or without amifostine in locally advanced lung cancer. Semin in Radiat Oncology 2002; 12: 46-9.

35. Komaki R, Lee JS, Kaplan B, Allen P, Kelly JK, Liao Z, et al. Chemoradiation with or without amifostine for patients with favorable performance status inoperable stage II-III non small cell lung cancer: Preliminary results. Semin in Radiat Oncology 2002; 12: 46-9.

36. Marks LB, Munley MT, Bentel GC et al. Physical and biological predictors of changes in whole-lung function following thoracic irradiation. Int J Radiat Oncol Biol Phys 1997; 39: 563-70.

37. Theuws JC, Muller SH, Seppenwoolde et al. Effect of radiotherapy and chemotherapy on pulmonary function after treatment for breast cancer and lymphoma: A follow-up study. J Clin Oncol 1999; 17: 3091-100.

38. Thames HD, Withers HR, Peters $U$, et al. Changes in early and late radiation responses with altered dose fractionation: implications for dose-survival relationships. Int J Radiat Oncol Biol Phys 1982; 8: 219.

39. Yamada M, Kudoh S, Hirata K et al. Risk factors of pneumonitis following chemoradiotherapy for lung cancer. Eur J Cancer 1998; 34: 71

40. Khan MA, Hill RP, Van Dyk. Partial volume rat lung irradiation: an evolution of early DNA damage. Int J Radiat Oncol Biol Phys 1998; 40: 467

41. Seppenwoolde Y, Lebesque JV, De Jaeger K, Belderbos JS, Boersma $\sqcup$, Schilstra $C$ et al. Comparing different NTCP models that predict the incidence of radiation pneumonitis. Int J Radiat Oncol Biol Phys 2003; 55: 724-35.

42. Tsujino $K$, Hirota $S$, Endo $M$, Obayashi $K$, Kotani $Y$, Satuchi $M$, et al. Int J Radiat Oncol Biol Phys 2003; 55: 110-15.

43. Graham MV , Purdy JA, Emani B et al. Clinical dose-volume histogram analisis for pneumonitis after 3D treatment for nonsmall cell lung cancer (NSCLC). Int J Radiat Oncol Biol Phys 1999; 45: 323-9

44. Jenkins P, D'amico K, Benstead K, Elyan S. Radiation pneumonitis following treatment of non-small-cell lung cancer with con- 


\section{F. Casas y cols.}

tinuous hyperfractionated accelerated radiotherapy (CHART). Int J Radiat Oncol Biol Phys 2003; 56: 360-6.

45. Hernando Ml, Marks LB, Bentel GC, Zhou S-M, Hollis D, Das SK et al. Radiatio-induced pulmonary toxicity: a dose-volume histogram analysis in 201 patinets with lung cancer. Int J Radiat Oncol Biol Phys 2001; 51:650-9.

46. Dileto CL, Travis EL. Fibroblast radiosensitivity in vitro and lung fibrosis in vivo: comparison between a fibrosis-prone and fibrosis-resistant mouse strain. Radiat Res 1996; 146: 61-67.

47. Geara FB, Komaki R, Tucker SL, Travis EL, Cox JD. Factors influencing the development of lung fibrosis after chemoradiation for small cell carcinoma of the lung: evidence for inherent interindividual variation. Int J Radiat Oncol Biol Phys 1998; 41 279-86.

48. Anscher M, Murase T, Prescott DM, Marks LB, ReisenbichelerH, Bentel GC. Changes in plasma TGF beta levels during pulmonary radiotherapy as a predictor of the risk of developing radiation pneumonitis. Int J Radiat Oncol Biol Phys 1994; 671-6.

49. Fu X-L,Huang H, Bentel G, Clough R, Jirtle RL, Kong F-M, et al Predicting the risk of symptomatic radiatio-induced lung injury using both the physical and biological parameters V 30 and transforming growth factor beta. Int J Radiat Oncol Biol Phys 2001;50:899-908.

50. Anscher MS, Marks LB, Shafman TD, Clough R, Huang H, Tisch $A$, et al. Using plasma trasforming growth fcator beta-1 during radiotherapy to select patients for dosze escalation. J Clin Oncol 2001;19:3758-65.

51. Gopal R, Starkschall G, Tucker SL, Cox JD, Liao Z, Hanus M et al. Effects of radiation and chemotherapy and chemotherapy on lung function in patients with non-small-cell lung cancer. Int J Radiat Oncol Biol Phys 2003; 56: 114-200.

52. Rübe $C E$, Wiffert $F$, Uthe D, Schmid KW, Knoop R, Willich $N$, et al. Modulation of radiation-induced tumour necrosis factor alfa (TNF-alfa) expression in the lung tissue by pentoxifyline. Radiother and Oncolo 2002; 64:177-87.
53. Martel MK, Sahijdak WM, Ten Haken RK, Kessler ML, Turrisi AT. Fraction size and dose parameters related to the incidence of pericardial effusions. Int J Radiat Oncol Biol Phys 1998;40:155-161.

54. Sandri MT, Cardinale D, Zorzino L, Passerini R, Lentati P, MartinoniA, et al. Minor increases in plama troponin I predict dedreased left ventricular ejection fraction after high-dose chemotherapy. Clin Chem 2003; 49: 248-52.

55. Hammack JE, Michalak JC, Loprinzi CL, Sloan JA, Novotny PJ, Soori GS et al. Phase III evaluation of nortriptyline for allevaition of symptoms of cis-platinum- induced peripheralneuropathy. Pain 2002; 98: 195-203.

56. Pace A, Savarese A, Picardo M, Maresca V, Pacceti U, Del Monte , G, et al. Neuroprotective effect of antioxidant supplementation with vitamin $E$ in patients treated with cisplatin chemotherapy. J CO 2003;21:927-31.

57. Yuen AR, Zou G, Turrisi AT, Sause W, Komaki R, Wagner $H$, Aisner SC, Livingston RB, Blum R, Johnson DH. Similar outcome of elderly patients in intergroup trial 0096: Cisplatin, etoposide, and thoracic radiotherapy administered once or twice daily in limited stage small cell lung carcinoma. Cancer 2000; 89: 1953-60.

58. Baraldi-Junkins CA, Beck AC,Rothstein G. Hematopoiesis and cytokines. Relevance to cancer and aging. Hematol Oncol Clin North Am 2000;14:45-61.

59. Balducci L, Hardy CL. Anemia of aging: a model of erythropoiesis in cancer patients. Cancer Control 1998; 19: 327-38.

60. Pierelli L, Perillo A, Greggi S, et al. Erythropoietin addition to granulocyte colony-stimulating factor abrogates life-threatening neutropenia and increases peripheral-Blood progenitor-cell mobilization after epirubicin, placlitaxel and cisplatin combination chemotherapy: results of a randomized comparasion. J Clin Oncol 1998; 16: 226-33.

61. Balducci L, Hardy Ch L, Lyman GH. Hemopoietic reserve in the older cancer patient: clinical and economic considerations. Cancer control 2000; 7: 539-47. 